\title{
Influence of Ultraviolet-ray Irradiation on the Mechanical and Electrical Properties of Polylactic Acid
}

\author{
Katsuyoshi SHINYAMA and Shigetaka FUJITA \\ Department of Electrical and Electronic Systems, Hachinohe Institute of Technology \\ 88-1, Myo Ohbiraki, Hachinohe 031-8501, JAPAN \\ E-mail: shinyama@hi-tech.ac.jp
}

\begin{abstract}
Polylactic acid (PLA) is a biodegradable, eco-friendly plastic that is attracting more attention than any other plastic of its kind. In this study, the authors examined the effects of ultraviolet light on the mechanical and electrical characteristics of PLA in order to clarify the prospects of using PLA as an electrical insulator material. An examination of the tensile stress curves versus the elongation showed that the stress and elongation of PLA decreased with an increase in the time length of the UV irradiation and that this decrease in the elongation was significant. The authors found that the dielectric breakdown strength $\left(E_{\mathrm{B}}\right)$ is temperature dependent; that is, with an increase in the time length of the UV irradiation, the $E_{\mathrm{B}}$ of PLA had a tendency to decrease over a wide temperature range.
\end{abstract}

Key Words : biodegradable plastics, polylactic acid, mechanical properties, electrical properties, ultraviolet-ray irradiation

\section{INTRODUCTION}

One of the current issues stemming from growing concerns over the prospect of oil depletion is the recycling of wire coating materials such as vinyl chloride and polyethylene. Today, almost all the copper and aluminum used for electric wire are recycled because they are valuable substances. However, since the materials used to coat electric wire are not regarded as recyclable under the current recycling system, most of these materials are disposed of as industrial waste, the exception being those used in the recycling operations of wire manufacturers. With demand for the recycling of wire coating materials increasing, growing attention is being paid to the use of electrical wire with a polyethylene coating as it is an eco-friendly material (EM). Since polyethylene is made from petroleum, it is clear that a replacement will be required in the near future. The authors have focused their attention on biodegradable plastics as they are even more eco-friendly.

Biodegradable plastics can be used just like other general plastic materials and, once they are disposed of, they are decomposed by microbes, eventually breaking down into carbon dioxide and water. Polylactic acid (PLA), which is a biomass plastic, is attracting greater attention than other biodegradable plastics of its kind because it is produced by the polymerization of lactic acids derived from the fermentation of corn or other plants [1-2]. However, PLA is rarely used to provide electrical insulation due to a lack of knowledge about its electrical insulation properties. Many papers have been published on the electrical characteristics of PLA, including a number of papers by the authors [3-15]. In their papers, the authors have examined the mechanical and electrical characteristics of PLA in a bid to promote its application as an electrical insulation material [3-9]. Their research revealed that the glass transition temperature $\left(T_{\mathrm{g}}\right)$ of PLA is between 60 and $70^{\circ} \mathrm{C}$ and that its mechanical performance falls dramatically at temperatures above that. It is therefore advisable that PLA at a temperature below its $T_{\mathrm{g}}$ be used in the coating of electric wire. Moreover, since PLA is a thermoplastic resin, it can be recycled after it has been used as an electric wire coating.

Earlier papers published by the authors have shown that the electrical resistivity of PLA is higher than that of low-density polyethylene (LDPE) at room temperature, and that the dielectric breakdown strength $\left(E_{\mathrm{B}}\right)$ of PLA at room temperature is roughly 1.4 times greater than that of LDPE [9]. In this study, the authors examined the effects of ultraviolet (UV) radiation on the mechanical and electrical characteristics of PLA in order to assess PLA's durability. To analyze these effects, the authors also carried out a thermal analysis and surface analysis of the PLA.

\section{EXPERIMENTAL METHODS}

In their experiments, the authors used biaxial-stretched films of PLA (Palgreen LC, thickness: $25 \mu \mathrm{m}$ ) manufactured by Tohcello Co., Ltd. as the samples. Figure 1 shows the chemical structural formula of PLA.

An earlier paper published by the authors showed that the irradiation of long-wavelength UV radiation (UV-A, wavelength:<smiles>CC(C)C(=O)O</smiles>

Figure 1 Chemical structure of PLA. 
$365 \mathrm{~nm}$ ) had little effect on the electrical properties of PLA [10]. In this study, the authors irradiated the samples with short-wavelength UV light (UV-C; wavelength: $254 \mathrm{~nm}$ ) in air at room temperature. Although UV-A (wavelength: 315-400 $\mathrm{nm}$ ) and UV-B (wavelength: 280-315 nm) reach the surface of the Earth, UV-C (wavelength: $100-280 \mathrm{~nm}$ ) is absorbed by the atmosphere so UV radiation of this wavelength range does not reach the Earth's surface. In other words, the photon energy emitted by the UV lamp used in this study is considerably more powerful than that of the UV radiation that reaches the surface of the Earth, resulting in the samples being exposed to more severe irradiation conditions than would be the case in nature. Each sample was irradiated for up to three hours with UV light with an intensity of approximately $1 \mathrm{~mW} /$ $\mathrm{cm}^{2}$. Figure 2 shows an outline illustration of the UV irradiating equipment. Although the temperature of each sample rose by several degrees as a result of the UV irradiation, the authors were able to confirm that this temperature did not exceed the $T_{\mathrm{g}}$ of PLA.

For the mechanical test in air at room temperature, test pieces were prepared in accordance with JIS K 7127. Each test piece was $25 \mathrm{~mm}$ wide, $150 \mathrm{~mm}$ long, and had a width of $6 \mathrm{~mm}$ across its stretched section. Two parallel lines spaced $25 \mathrm{~mm}$ apart were marked at the center of each test piece.

After the UV irradiation stage, aluminum film electrodes with a diameter of $25 \mathrm{~mm}$ were formed by vapor deposition on either side of each test piece to enable the dielectric properties and electrical resistivity to be measured. The measurements were carried out while the temperature of the samples was increased in dry air.

In the dielectric breakdown strength test, a DC voltage $(1 \mathrm{kV} /$ $\mathrm{sec}$ ) was applied to a test piece in silicone oil while the temperature of the oil was adjusted using the same measuring system as that used for the mechanical test [9]. The strength was obtained by dividing the dielectric breakdown voltage by the thickness of the test piece.

The authors used a heat flux differential scanning calorimeter (DSC) (Shimadzu Corporation, DSC-60) for the thermal analysis. The standard sample was made of $\alpha$-alumina. The DSC curves for PLA were observed while the temperature was increased at the rate of $10^{\circ} \mathrm{C} / \mathrm{min}$ in a nitrogen gas atmosphere from $30^{\circ} \mathrm{C}$ to $230^{\circ} \mathrm{C}$.

An X-ray photoelectron spectrometer (XPS) (JEOL Ltd., JPS9000) was used for the surface analysis. The X-ray source voltage was set to $10 \mathrm{kV}$, and the emission current to $10 \mathrm{~mA}$.

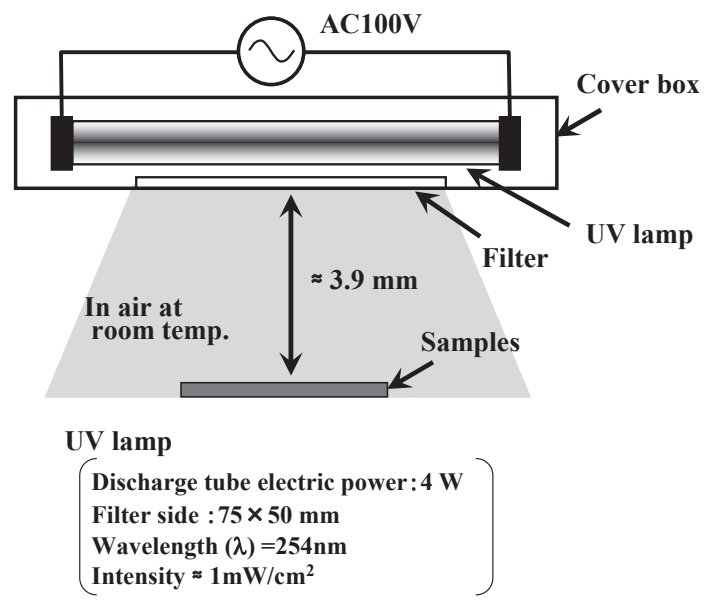

Figure 2 UV irradiating equipment.

\section{RESULTS AND DISCUSSION}

The authors carried out the thermal analysis first using the DSC. Figure 3 shows the DSC curves for UV-irradiated PLA. The glass transition temperatures $\left(T_{\mathrm{g}}\right)$ and the melting points $\left(T_{\mathrm{m}}\right)$ of PLA were then derived from the DSC curves, as shown in Figures 4 and 5, respectively. PLA's $T_{\mathrm{g}}$ and $T_{\mathrm{m}}$ had a tendency to decrease with an increase in the time length of UV irradiation, suggesting that the UV irradiation caused intermolecular breaks in the PLA.

Figure 6 shows changes in the tensile stress and the elongation curve of PLA as a function of the time length of UV irradiation. The tensile stress and the elongation decreased as the time length of irradiation increased. The UV irradiation significantly reduced the elongation. Taking this into account, along with the data shown in Figures 4 and 5, the authors concluded that the mechanical strength of the PLA was reduced by intermolecular breaks in the PLA caused by the UV irradiation.

Figure 7 shows the temperature dependencies of the relative permittivity $\left(\varepsilon_{\mathrm{r}}^{\prime}\right)$ and the imaginary part of the complex relative permittivity or the dielectric loss factor $\left(\varepsilon_{\mathrm{r}}{ }^{\prime \prime}\right)$ at $f=1 \mathrm{kHz}$. The $\varepsilon_{\mathrm{r}}{ }^{\prime}$ and $\varepsilon_{\mathrm{r}}$ " of UV-irradiated samples were higher than those of non-

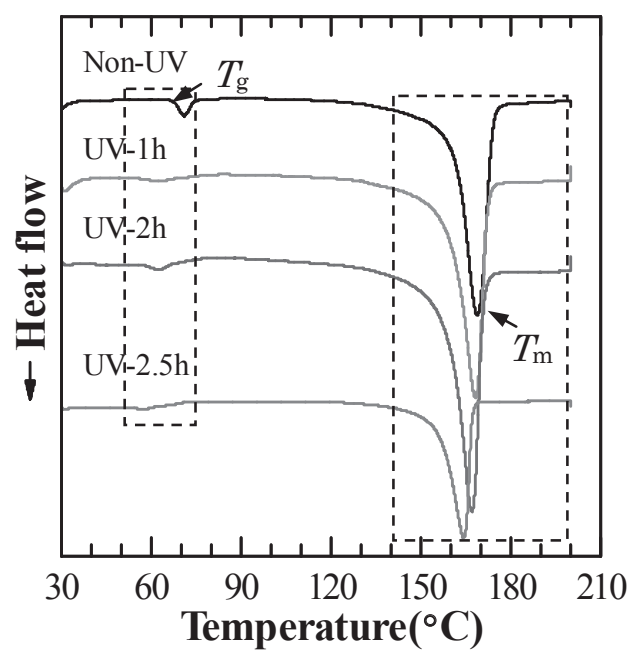

Figure 3 DSC curves of PLA.

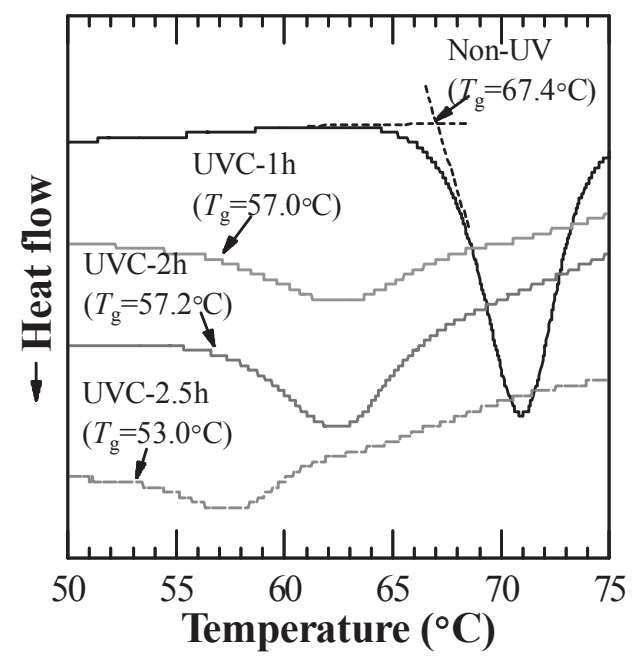

Figure 4 Glass transition temperatures $\left(T_{\mathrm{g}}\right)$ of PLA. 


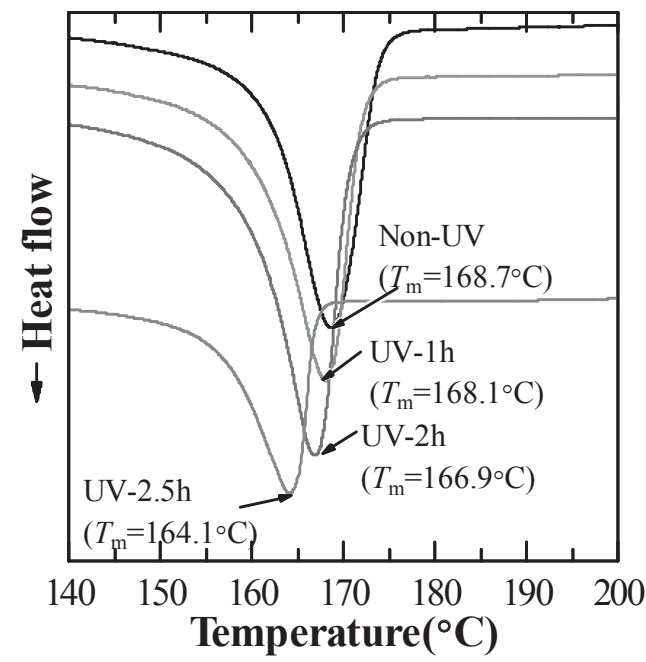

Figure 5 Melting points $\left(T_{\mathrm{m}}\right)$ of PLA.

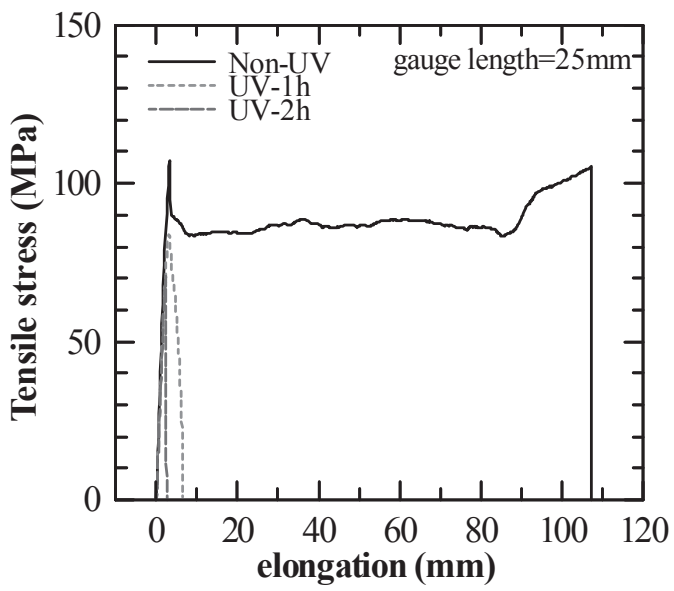

Figure 6 Changes in the tensile stress and the elongation curve of PLA.

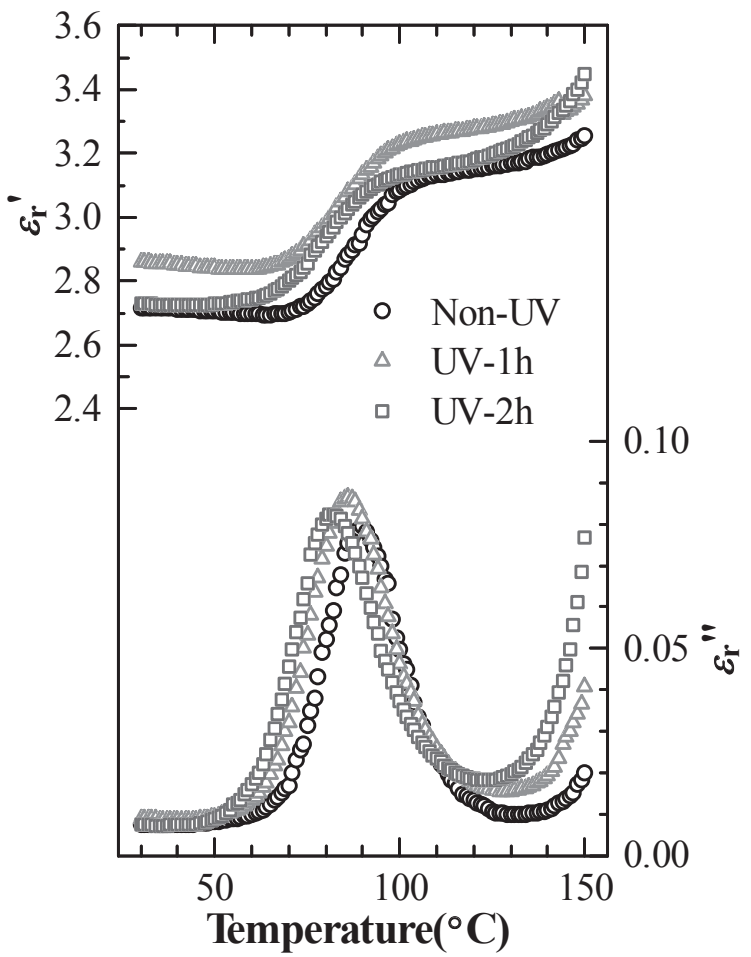

Figure 7 Temperature dependencies of $\varepsilon_{\mathrm{r}}^{\prime}$ and $\varepsilon_{\mathrm{r}}{ }^{\prime \prime}$ at $f=1 \mathrm{kHz}$.
Table 1 Dielectric parameters of PLA at $95^{\circ} \mathrm{C}$

\begin{tabular}{c|c|c|c|c|c|c}
\hline & $\varepsilon_{\mathrm{r} \infty}$ & $\varepsilon_{\mathrm{r} 0}$ & $\Delta \varepsilon$ & $\alpha$ & $\beta$ & $\tau_{0}(\mu \mathrm{s})$ \\
\hline \hline Non-UV & 2.56 & 3.18 & 0.57 & 0.24 & 0.38 & 15.9 \\
\hline UV-1h & 2.53 & 3.33 & 0.62 & 0.14 & 0.37 & 5.05 \\
\hline UV-2h & 2.38 & 3.20 & 0.63 & 0.13 & 0.37 & 1.59 \\
\hline
\end{tabular}

UV-irradiated samples. This suggests that the UV irradiation broke some of the molecular chains in the PLA, causing the electrical polarization to increase with time. Moreover, the temperature at which the $\varepsilon_{\mathrm{r}}^{\prime}$ and $\varepsilon_{\mathrm{r}}^{\prime \prime}$ of a UV-irradiated sample began to increase rapidly was lower than that of the non-UV-irradiated samples. As Figure 5 shows, the UV irradiation reduced the $T_{\mathrm{g}}$, which in turn reduced the temperature at which micro-Brownian motion begins, creating conditions in which orientation polarization can more easily occur.

Figure 8 shows the frequency dependencies of $\varepsilon_{\mathrm{r}}^{\prime}$ and $\varepsilon_{\mathrm{r}}{ }^{\prime \prime}$ at $95^{\circ} \mathrm{C}$. The absorption peak of $\varepsilon_{\mathrm{r}}$ " shifted to the high frequency region with an increase in the time length of UV irradiation. The complex permittivity $\left(\varepsilon_{\mathrm{r}}^{*}\right)$ of a polymer can be expressed with the HavriliakNegami relaxation function shown in Equation (1) below, where $\varepsilon_{0}$ and $\varepsilon_{\infty}$ are limiting low- and high-frequency dielectric constants, respectively, $\omega$ is the angular frequency, $\tau_{0}$ is the mean relaxation time, and $\alpha$ and $\beta$ are distribution parameters [16].

$$
\varepsilon_{\mathrm{r}}^{*}=\varepsilon_{\infty}+\frac{\varepsilon_{\infty}-\varepsilon_{\infty}}{\left(1+\left(j \omega \tau_{0}\right)^{\beta}\right)^{\alpha}}
$$

The authors found that the results shown in Figure 8 were approximated by Equation (1). The dielectric parameters calculated from the data shown in Figure 9 are given in Table 1. Figure 9 shows a plot of the $\varepsilon_{\mathrm{r}}^{\prime}$ and $\varepsilon_{\mathrm{r}}^{\prime \prime}$ at $95^{\circ} \mathrm{C}$, with a dotted line showing an approximated curve. As shown in this figure, the authors were generally able to fit the actual measurements to the approximation

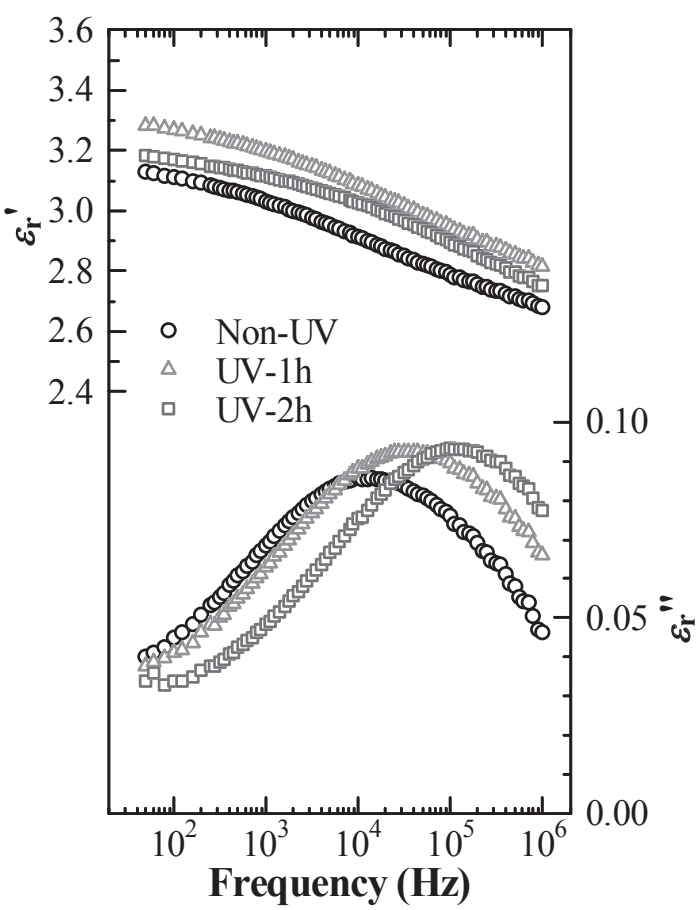

Figure 8 Frequency dependencies of $\varepsilon_{\mathrm{r}}^{\prime}$ and $\varepsilon_{\mathrm{r}}^{\prime \prime}$ at $95^{\circ} \mathrm{C}$. 
curve. The relaxation strength $(\Delta \varepsilon)$ can be calculated by subtracting $\varepsilon_{\infty}$ from $\varepsilon_{0} . \Delta \varepsilon$ rose with an increase in the time length of UV irradiation. Moreover, the relaxation time shortened and $\alpha$ fell as the time length of UV irradiation increased. It has been observed for many polymers that $\Delta \varepsilon$ increases with a fall in the degree of crystallinity [17]. Moreover, the relaxation time is higher and the value of $\alpha$ is lower for crystalline polyetheretherketone (PEEK) than for amorphous PEEK [18]. The authors therefore surmised that the molecular bonds in the crystalline region were broken by the UV irradiation.

Figures 10 and 11 show the temperature dependencies of the volume resistivity and the surface resistivity of PLA, respectively, when a static electric field of $0.2 \mathrm{MV} / \mathrm{cm}$ is being applied. The volume resistivity and surface resistivity of all samples fell with a rise in temperature. However, resistivity was observed to begin to rise when the temperature rose above $50^{\circ} \mathrm{C}$ and approached $60^{\circ} \mathrm{C}$. This was caused by the dipoles, which had originally been oriented in random directions, becoming aligned as the temperature of the sample approached the $T_{\mathrm{g}}$. Moreover, this phenomenon was observed more often with UV-irradiated samples at low temperatures than with non-UV-irradiated samples. When a high temperature of $60^{\circ} \mathrm{C}$ or more was reached, a tendency for the volume resistivity and the surface resistivity of a sample to fall again with a rise of a temperature was observed. This fall was found to be more pronounced for UV-irradiated samples

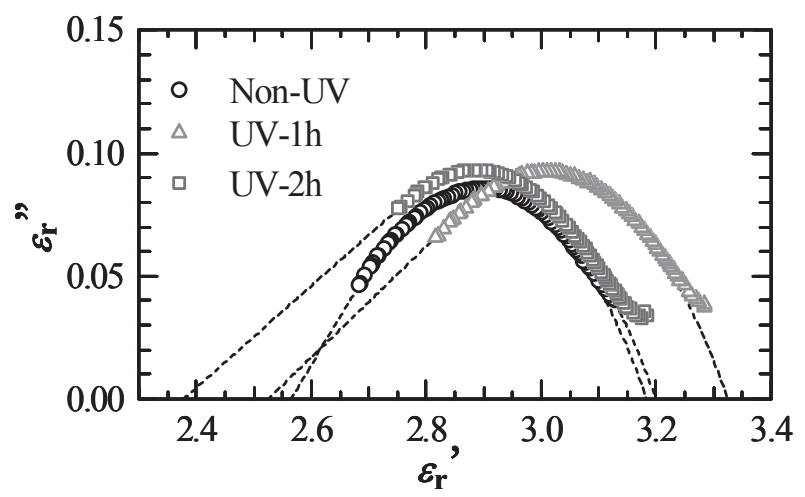

Figure 9 The plots using Equation of Havriliak-Negami type relaxation of PLA .

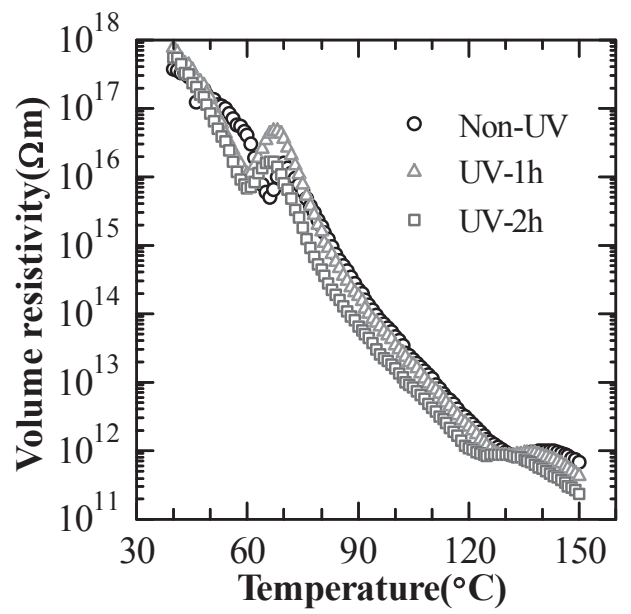

Figure 10 Temperature dependencies of the volume resistivity of PLA. than non-UV-irradiated samples. The data in Figures 10 and 11 agree with the results obtained by Yamaguchi et al., who reported that electric current conductivity on PLA increased after it was irradiated with UV light (wavelength: $222 \mathrm{~nm}$, intensity: $5.5 \mathrm{~mW} /$ $\mathrm{cm}^{2}$ ) for 30 minutes under a $\mathrm{KrCl}$ excimer lamp [15]. Both the volume resistivity and the surface resistivity curves have small peaks at around $70^{\circ} \mathrm{C}$, which is close to the $T_{\mathrm{g}}$, implying that there are biased dipoles in the material. The temperature at which these peaks appear falls as the time length of the UV irradiation increases. The authors found that the UV irradiation caused ion conduction based on these data.

Figure 12 shows the temperature dependency of the dielectric breakdown strength $\left(E_{\mathrm{B}}\right)$ of UV-irradiated PLA. The $E_{\mathrm{B}}$ of PLA has a tendency to decrease over a wide temperature range as the time length of the UV irradiation increases, leading to the conclusion that the UV irradiation lowered the $E_{\mathrm{B}}$ of PLA.

As shown in Figures 6 through 12, the mechanical and electrical properties of PLA degraded after UV irradiation. In order to find the specific causes, the authors examined UV-induced structural changes on the surface of the test pieces by performing a surface

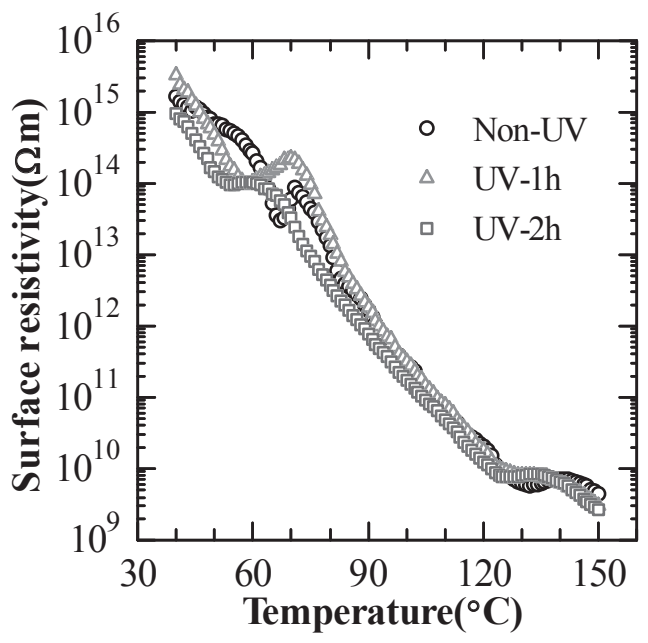

Figure 11 Temperature dependencies of the surface resistivity of PLA.

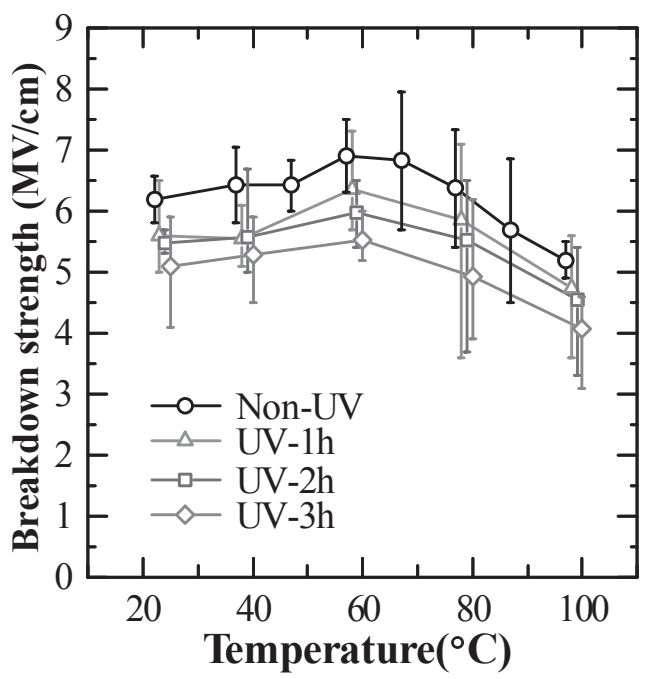

Figure 12 Temperature dependency of the dielectric breakdown strength of PLA. 
analysis with an XPS analyzer. Figure 13 shows changes in the strength of each molecular bond site on the surface, which were derived from the waveform separation of the $\mathrm{C} 1 \mathrm{~s}$ spectrum of PLA. The spectrum peak of a $\mathrm{C}-\mathrm{H}$ bond around $285 \mathrm{eV}$ decreased after the UV irradiation. Peaks of $\mathrm{C}-\mathrm{O}$ and $\mathrm{O}-\mathrm{C}=\mathrm{O}$ around $287 \mathrm{eV}$ and $289 \mathrm{eV}$ slightly increased after the UV irradiation. Figure 14 shows changes in the strength of each molecular bond site on the surface after the UV irradiation which were derived from the waveform separation of the O1s spectrum of PLA. Peaks of $\mathrm{C}=\mathrm{O}$ and $\mathrm{O}-\mathrm{C}=\mathrm{O}$ around $532 \mathrm{eV}$ and $533 \mathrm{eV}$ increased after the UV irradiation. The bonding energies of $\mathrm{C}-\mathrm{O}, \mathrm{C}-\mathrm{H}$, and $\mathrm{C}=\mathrm{O}$ are $3.6 \mathrm{eV}$, $4.3 \mathrm{eV}$, and $7.5 \mathrm{eV}$, respectively. Since the energy of the UV-C lamp used in this study was $4.9 \mathrm{eV}$, the UV irradiation easily broke the molecular bonds of $\mathrm{C}-\mathrm{O}$ or $\mathrm{C}-\mathrm{H}$. Therefore the authors believe that UV irradiation broke some of the molecular chains on the PLA surface to generate radicals, which combined with oxygen atoms producing a substance with a low molecular weight. Degradation reactions by oxidization were also accelerated.

\section{CONCLUSIONS}

PLA is a biodegradable, eco-friendly plastic that is attracting more attention than any other plastic of its kind. In this study, the

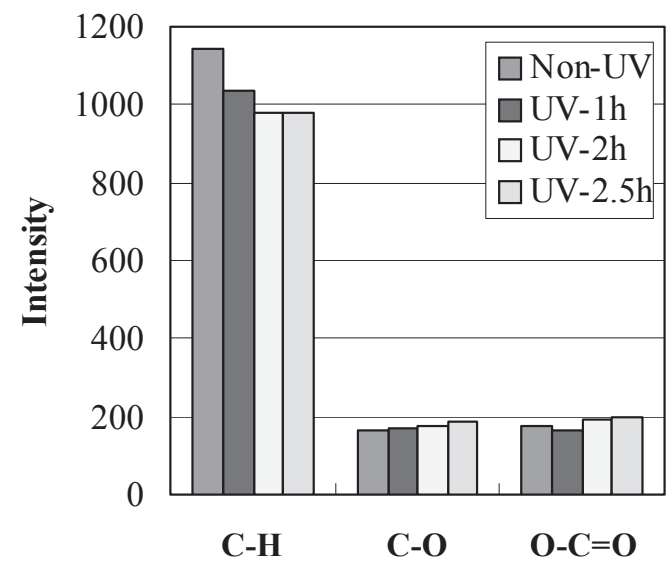

Figure 13 Changes in strength of each molecular bond site on the surface, which were derived from waveform separation of the $\mathrm{C} 1 \mathrm{~s}$ spectrum of PLA.

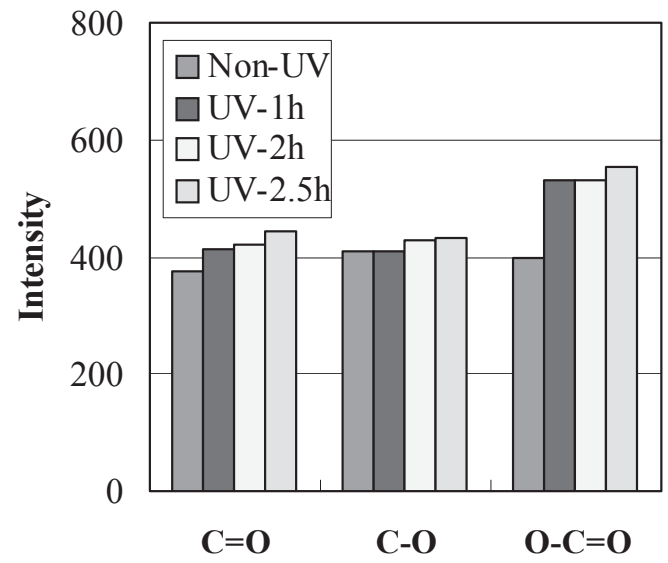

Figure 14 Changes in strength of each molecular bond site on the surface, which were derived from waveform separation of the $\mathrm{O} 1 \mathrm{~s}$ spectrum of PLA. authors examined the effects of UV light on the mechanical and electrical characteristics of PLA in order to clarify the prospects of using PLA as an electrical insulator material. The results were as follows.

(1) The tensile stress curves versus the elongation show that the stress and elongation of PLA decreased with an increase in the time length of the UV irradiation and that this decrease in the elongation was significant.

(2) The relative permittivity $\left(\varepsilon_{\mathrm{r}}^{\prime}\right)$ and dielectric loss factor $\left(\varepsilon_{\mathrm{r}}{ }^{\prime \prime}\right)$ of PLA at $f=1 \mathrm{kHz}$ are temperature dependent; that is, with an increase in the time length of the UV irradiation, the $\varepsilon_{\mathrm{r}}{ }^{\prime}$ and $\varepsilon_{\mathrm{r}}{ }^{\prime \prime}$ of PLA had a tendency to increase and the temperatures at which $\varepsilon_{\mathrm{r}}{ }^{\prime}$ and $\varepsilon_{\mathrm{r}}$ " started to increase fell.

(3) The volume resistivity and the surface resistivity of PLA with a static electric field of $0.2 \mathrm{MV} / \mathrm{cm}$ are temperature dependent; that is, with an increase in the time length of the UV irradiation, the volume resistivity and the surface resistivity of PLA had a tendency to decrease over a wide temperature range.

(4) The dielectric breakdown strength $\left(E_{\mathrm{B}}\right)$ is temperature dependent; that is, with an increase in the time length of the UV irradiation, the $E_{\mathrm{B}}$ of PLA had a tendency to decrease over a wide temperature range.

\section{Acknowledgments}

This work was supported by a targeted project research subsidy from the Hachinohe Institute of Technology. The authors would like to thank Tohcello Co., Ltd. for supplying the test samples.

\section{References}

[1] Y. Inoue et al.: "Recent Advances in Research and Development for Green Plastics", CMC Publishing Co., Ltd., Tokyo (2002) (in Japanese).

[2] H. Tsuji: "Biodegradable Polymers", Corona Publishing Co., Ltd., Tokyo (2002) (in Japanese).

[3] K. Shinyama and S. Fujita: "Fundamental Study on Electrical Properties of Biodegradable Plastics", Proc. of the 4th International Conference on Materials Engineering for Resources (ICMR2001), Vol.2, pp.284-287, (2001).

[4] K. Shinyama and S. Fujita: "Study on the Electrical Properties of a Biodegradable Plastic", Proc. of the 7th International Conference on Properties and Applications of Dielectric Materials (ICPADM2003), Vol.2, pp.707-710, (2003).

[5] K. Shinyama and S. Fujita: "Electrical Properties of Biodegradable Plastics", Proc. of the International Conference on Electrical Engineering (ICEE2004), Vol.1, pp.357-360, (2004).

[6] K. Shinyama and S. Fujita: "Electrical Conduction and Dielectric Properties of Biodegradable Plastics", T. IEE Japan, Vol.125-A, No.3, pp.204-208, (2005) (in Japanese).

[7] K. Shinyama and S. Fujita: "Mechanical and Electrical Properties of Biodegradable Plastics", Proc. of 2005 International Symposium on Electrical Insulating Materials (ISEIM2005), Vol.3, pp.775-779, (2005).

[8] K. Shinyama and S. Fujita: "Mechanical and Electrical Properties of Eco-Friendly Dielectric Materials", Proceedings of the Fifth International Conference on Materials Engineering for Resources (ICMR2005), pp.291296, (2005).

[9] K. Shinyama and S. Fujita: "Mechanical and Dielectric 
Breakdown Properties of Biodegradable Plastics", IEEJ Trans. FM, Vol. 126-A, No.1, pp.31-36, (2006).

[10] K. Shinyama and S. Fujita: "Influence of Ultraviolet Irradiation on Biodegradable Plastics", 2005 National Convention Record IEE Japan, Vol.2, p.30, (2005) (in Japanese).

[11] T. Nakagawa, T. Nakiri, R. Hosoya and Y. Tajitsu: "Electrical Properties of Biodegradable Polylactic Aced Film", IEEE Transactions on Industry Applications, Vol.40, No.4, pp.1020-1024, (2003).

[12] F. Kato, M. Matsushita, S. Omori, and Y. Ohki: "Effect of Endothermic Reaction Associated with Glass Transition on the Breakdown Strength of Biodegradable Polymer Films", IEEE Transactions on DEI, Vol.14, No.3, pp.653-655, (2007).

[13] K. Miyata, S. Fujita, Y. Ohki and T. Tanaka: "Comparison of Partial Discharge Resistance among Several Biodegradable
Polymers", IEEE Trans. DEI, Vol.14, No.6, pp.1474-1476, (2007).

[14] Y. Ohki and N. Hirai: "Electrical Conduction and Breakdown Properties of Several Biodegradable Polymers", IEEE Trans. DEI, Vol.14, No.6, pp.1559-1567, (2007).

[15] Y. Yamaguchi, N. Uchibori and Y. Ohki: "Effects of Ultraviolet Photon Irradiation on the Dielectric Properties of Biodegradable Polymers", IEEJ Trans. FM, Vol.127-A, No.2, pp.115-120, (2007) (in Japanese).

[16] The Society of Polymer Science, Japan, "The foundation of polymer science", Tokyo Kagaku Dojin Co., 1td., pp.247252, (1984) (in Japanese).

[17] E. Fukada et al., "Physics of Polymers", Asakura Publishing Co., ltd., pp.265-269, (1963) (in Japanese).

[18] Japan Society of Polymer Processing (JSPP), "A guide to high order structural analysis of plastic molding", NIKKAN KOGYO SHINBUN, pp.150-154, (2006) (in Japanese). 